\title{
Actinomicose intestinal: relato de caso
}

\author{
Intestinal actinomycosis: case report
}

\author{
KAISER DE SOUZA KOCH; EDUARDO ZEILMANN²; RICARDO BECKHAUSER KHUNEN³
}

\begin{abstract}
${ }^{1}$ Coloproctologista do Hospital Nossa Senhora da Conceição (HNSC); Professor da disciplina de Coloproctologia do curso de medicina da Universidade do Sul da Santa Catarina (UNISUL); Mestre em Ciências Médicas pela Universidade Federal de Santa Catarina (UFSC) - Florianópolis (SC), Brasil. ${ }^{2}$ Médico Residente do Serviço de Cirurgia Geral do HNSC - Tubarão (SC), Brasil. ${ }^{3}$ Médico residente do serviço de cirurgia geral do HNSC - Tubarão (SC), Brasil.
\end{abstract}

KOCH KDS; ZEILMANN E; KHUNEN RB. Actinomicose intestinal: relato de caso. Rev bras Coloproct, 2011;30(4): 459-461.

RESUMO: Relatamos o caso de paciente do sexo masculino, 48 anos, branco, trabalhador da zona rural, com queixa de dor abdominal tipo cólica associada a náuseas e vômitos havia 48 horas, desenvolvendo obstrução intestinal. A cavidade abdominal foi acessada por laparotomia, revelando duas áreas de estenose inflamatória no jejuno distal. Exame anatomopatológico revelou actinomicose abdominal, uma forma rara dessa doença.

Palavras-chave: Actinomicose, intestinal, obstrução do intestino.

\section{INTRODUÇÃO}

A actinomicose intestinal é uma infecção bacteriana crônica incomum de característica granulomatosa e supurativa ${ }^{1}$. É causada por uma bactéria Gram-positiva anaeróbia, normalmente encontrada na cavidade oral, sendo o Actinomyces israelli o agente etiológico mais frequente. Apesar de sua etiologia bacteriana, comporta-se como doença fúngica, tendo distribuição universal com maior frequência em países tropicais² ${ }^{2}$. Acomete principalmente trabalhadores das zonas rurais com higiene inadequada ou antecedentes de extração dentária ou cirurgia anterior ${ }^{3}$.

\section{RELATO DE CASO}

Paciente do sexo masculino, 48 anos de idade, branco, trabalhador da zona rural, natural e procedente de Mato Grosso do Sul (MS), com queixa de dor abdominal tipo cólica com dois dias de evolução associada a náuseas e vômitos e parada na eliminação de flatos e fezes. Negava sangramento via retal, emagrecimen- to, anorexia e hipertermia, e não apresentava alterações urogenitais, pulmonares e cardiovasculares. Ao exame físico, apresentava-se em bom estado geral, lúcido e orientado, eupneico, acianótico, anictérico, mucosas normocoradas e desidratadas $(++/ 4+)$. O abdômen estava distendido, ruídos hidroaéreos estavam ausentes, assim como sinais de irritação peritoneal. Os exames de bioquímica demonstravam discreta leucocitose sem desvio à esquerda com demais parâmetros normais. O exame de imagem evidenciou níveis hidroaéreos em diferentes posições e ausência de gás na ampola retal. Com diagnóstico sindrômico de abdômen agudo obstrutivo, o paciente foi encaminhado para tratamento cirúrgico.

A cavidade abdominal foi acessada por laparotomia mediana que evidenciou distensão de alças de delgado à custa de duas lesões estenóticas anelares (Figuras 1 e 2), amolecidas e de aspecto inflamatório em topografia de jejuno distal, distantes uma da outra em cerca de $10 \mathrm{~cm}$. O mesentério encontrava-se normal, sem sinais de linfonodopatias locorregionais palpáveis.

Ainda durante o inventário da cavidade, observou-se mais uma lesão estenótica com as mesmas

Trabalho Realizado no Serviço de Cirurgia Geral do Hospital Nossa Senhora da Conceição (HNSC), Sociedade Divina Providência - Tubarão (SC), Brasil.

$\overline{\text { Recebido em 31/03/2010 }}$

Aceito para publicação em 27/04/2010 


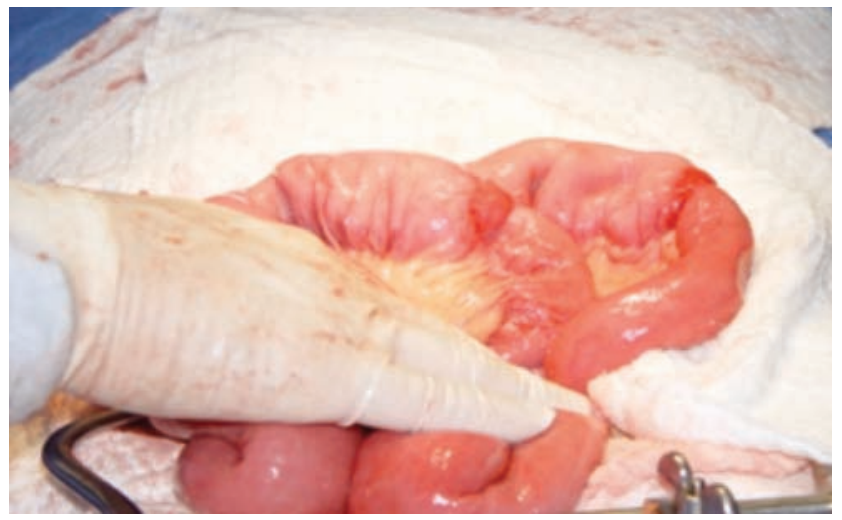

Figura 1 - Distensão de alças de delgado.

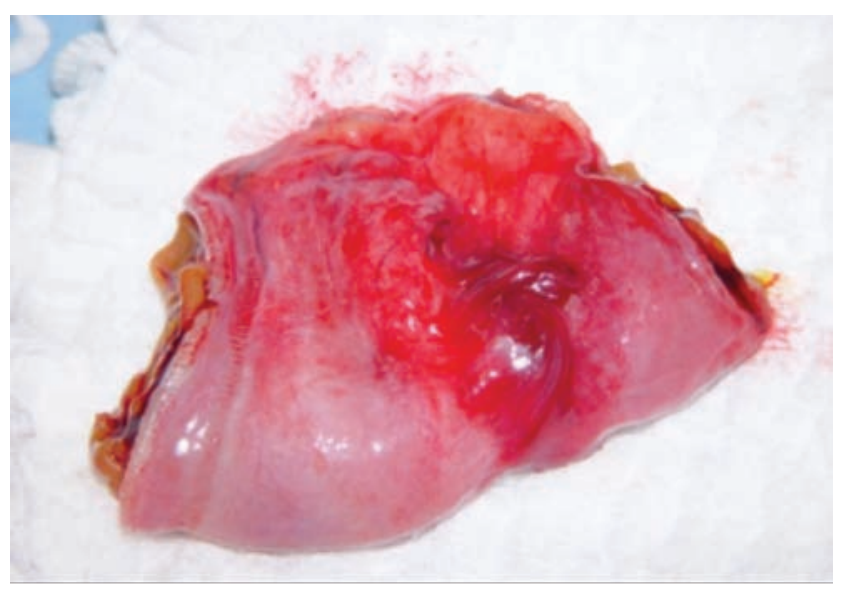

Figura 2 - Lesões estenóticas.

características macroscópicas das anteriores em cólon sigmoide (Figuras 3 e 4), causando obstrução parcial do lúmen intestinal. O restante dos órgãos e sistemas abdominais apresentava aspecto normal.

Realizou-se uma enterectomia englobando as duas lesões estenóticas de intestino delgado e uma retossigmoidectomia com anastomose primária. As peças cirúrgicas foram enviadas para estudo histopatológico. O paciente evolui bem, tendo recebido alta hospitalar no quinto dia pós-operatório. O resultado histopatológico revelou presença de processo granulomatoso não-caseoso com grânulos sulfurosos e infiltração neutrofílica em mesentério e mesocólon, compatível com actinomicose intestinal.

\section{DISCUSSÃO}

O envolvimento primário da actinomicose no intestino é raro, sendo a região ileocecal o local mais

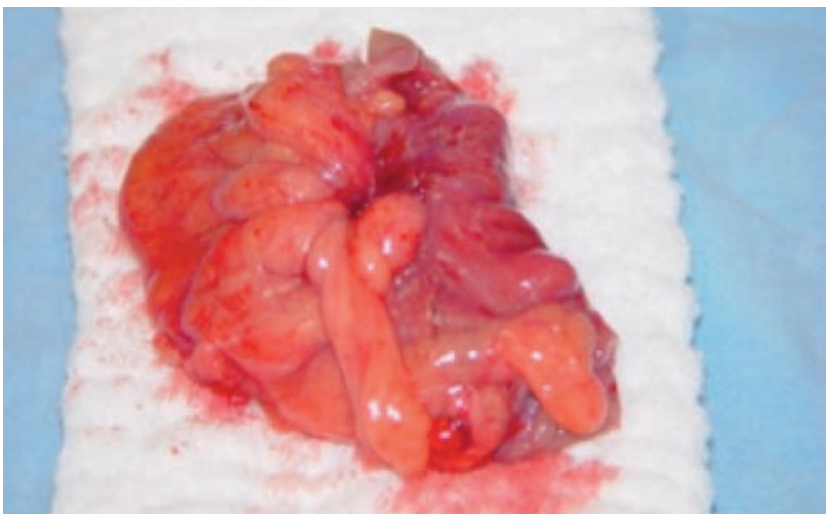

Figura 3 - Lesão estenótica.

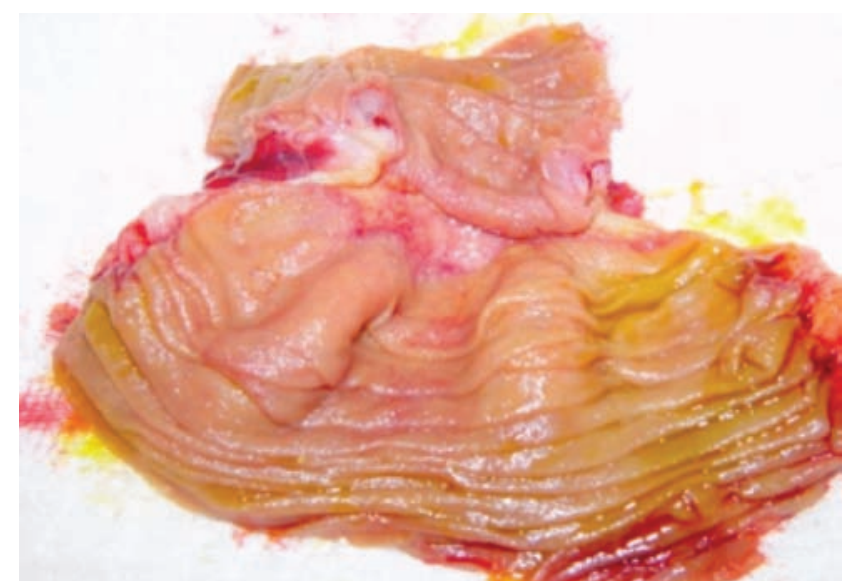

Figura 4 - Lesão estenótica. Peça aberta.

comum de acometimento ${ }^{4,5}$. Os actinomicetos, em especial o Actinomyces israelli, são bactérias anaeróbias ou facultativas, Gram-positivas, não ácido-resistentes e difíceis de serem cultivadas ${ }^{6-8}$. Se a resposta supurativa não erradica a bactéria, ocorre uma reação inflamatória granulomatosa característica seguida de intensa fibrose e necrose, com disseminação por contiguidade e sem respeitar os limites do órgão lesado, produzindo trajetos fistulosos ${ }^{8-10}$. Apresenta-se principalmente em três formas: cervicofacial (50\%), abdominal (20\%) e torácica $(20 \%)^{6,7,11}$.

Histologicamente, caracteriza-se por um processo supurativo granulomatoso (Abscessos) e fibrótico, neste caso acometendo o mesentério e mesocólon (Figura 5), onde os grânulos sulfurosos são corados por hematoxifilina-eosina e um centro basofílico com raias eosinofílicas ${ }^{5-8,10,11 .}$

A actinomicose intestinal envolve a apêndice cecal e íleo terminal em $65 \%$ dos casos, apresentan- 
do sinais e sintomas inespecíficos como hipertermia, perda de peso, constipação e dor abdominal. Os fatores predisponentes são: cirurgias abdominais prévias, corpos estranhos, apendicite, perfuração intestinal e neoplasias ${ }^{6,7}$. O diagnóstico pré-operatório é muito difícil, em torna de $10 \%$ dos casos; além disso, exames de imagem não são muito úteis para corroborar esta hipótese diagnóstica. A obstrução intestinal por actinomicose é muito rara, havendo poucos casos relatados na literatura científica ${ }^{6,10}$. Esta apresentação é uma indicação de tratamento cirúrgico, além dos casos em que não se consegue descartar doença neoplásica ${ }^{6,7,11}$. Nos casos não cirúrgicos, o tratamento com Penicilina por 4 a 6 meses é efetivo em $90 \%$ dos casos, sendo a Eritromicina e a Tetraciclina alternativas adequadas.

\section{CONCLUSÃO}

Abdômen Agudo Obstrutivo por Actinomycose intestinal é muito raro, e existem poucos casos relata-

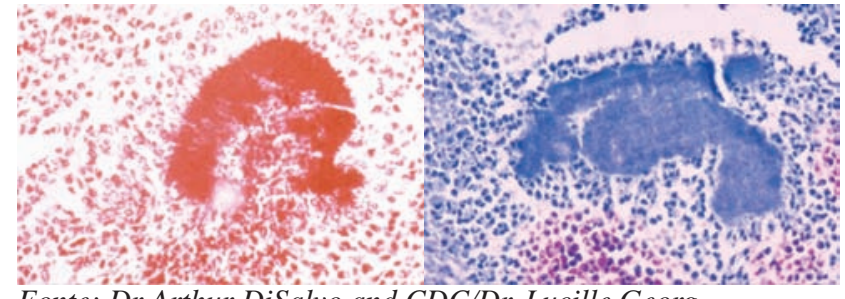

Fonte: Dr Arthur DiSalvo and CDC/Dr. Lucille Georg.

Figura 5 - Granuloma com grande infiltração neutrofilica e porção central basófila com grânulos.

dos na literatura científica. A doença ileocecal pode ser confundida com apendicite aguda, neoplasia de ceco, doença de Crohn, tuberculose intestinal e amebíase ${ }^{3,8}$. A presença de grânulos sulfurosos na histopatologia ocorre em $50 \%$ dos casos, sendo um dado altamente sugestivo da presença da doença. No entanto, o diagnóstico é determinado pela detecção da bactéria em meio de cultura que pode ocasionar resultados falsonegativos ${ }^{12}$.

ABSTRACT: We present a case of a 48-year-old Caucasian male farmer who was admitted to the hospital with cramping abdominal pain associated with nausea and vomiting for 48 hours, which developed large bowel obstruction. The abdominal cavity was accessed by laparotomy, showing two areas of inflammatory stenosis in distal jejunum. Anatomopathological examination showed abdominal actinomycosis, a rare presentation of this disease.

Key words: Actinomycosis, intestinal, bowel obstruction.

\section{REFERÊNCIAS}

1. Farthing MJG, Barsoum MM, Habr-Gama A. Coloproctologia tropical. In: Keighley MRB, Williams NS. Cirurgia do ânus, reto e colo. São Paulo: Manole; 1998; p. 2076-110.

2. Duellberg SH, Ferreira JFM, Mendes IA, et al. Actinomicose abdominal: análise de cinco casos e revisão da literatura. Rev Bras Coloproct 1989;9(2):67-71

3. Netinho JG, Cunrath GS, Silva J. Actinomicose de cólon direito. Rev Bras Coloproct 1999;19(1):19-21

4. Golingher J. Cirurgia do ânus, reto e colo. São Paulo: Manole; 1990.

5. Nayar E, Chandra M, Chitraratha K, Kumari Das S, Rai Chowdhary G. Incidence of Actinomycosis infection in women using contraceptive devices. Acta Cytol 1985;29(2)111-6.

6. Veronesi R, Focaccia R. Tratado de Infectologia. $2^{\mathrm{a}}$ ed. v. 2. São Paulo: Atheneu; 1996.

7. Bannura G. Abdominal actinomycosis. Rev Med Chile 1994;122(11):1307-15
8. Muller R, Winkler R, Dunker H, Heusermann H. Acute Abdomem in abdominal actinomycosis. Leber Magen Darm 1996;26(2):109-12.

9. Yeguez JF, Martinez S, Sands LR, Hellinger MD. Pelvic actinomycosis as malignant large bowel obstruction: A case report and a review of the literature. Am Surg 2000;66(1):85-90

10. Cintron JR, Del Pino A, Duarte B, Wood D. Abdominal actinomycosis. Dis Colon Rectum 1996;39(1):105-8

11. Chica FS, Ferrer FV, Del Pozo CD, et al. Abdominal actinomycosis simulation crohn's disease. Gastroenterol Hepatol 2001;24(6):300-2

12. Bittencourt JAF, Andreis EL, Lima EL, Dorn LD, Muller V. Actinomycosis Simulating Malignant large Bowel Obstruction. Braz J Infect Dis 2004;8(2):186-9. Epub 2004 Sep 8.

Endereço para correspondência:

Eduardo Zeilmann

Rua Felipe Schmidt, 265, apto. 403 - Centro

CEP 88701-435 - Tubarão (SC), Brasil

Tel.: (48) 3631-7000 / 9628-9727 